\title{
Regiones metropolitanas de Colombia: la gravitación y la desarticulación como rasgos dominantes de la organización territorial en curso
}

\author{
Metropolitan regions of Colombia: \\ gravitation and disarticulation as key rules \\ of the current territorial organization
}

Óscar A. Alfonso R.

\begin{abstract}
Resumen
En los albores de la paz, la necesidad de un nuevo modelo territorial de Estado se argumenta, de un lado, desde los entrabes al desarrollo que surgen del actual siendo el más evidente la corrupción administrativa. Del otro lado, desde tres experiencias relevantes que promueven las virtudes de la regionalización con base en las zonas metropolitanas; es decir, de las regiones metropolitanas. Y, por último, desde la viabilidad de mayores logros en autonomía local asumiendo plausibles costos impositivos soportados en la equidad en la tributación a la propiedad.
\end{abstract}

Palabras clave: metropolización; regiones metropolitanas; modernización del Estado.

\begin{abstract}
From the beginning, the need for a new territorial model of state arises, on the one hand, from the obstacles to development, among which the most evident is administrative corruption and, on the other hand, three relevant experiences that promote the virtues of regionalization based on metropolitan regions. Finally, the viability of local autonomy without greater tax burdens for the population if they were incurred with fairness in real estate taxation.
\end{abstract}

Keywords: metropolis; metropolitan regions; modernization of the state. 
La cesación del fuego producto de la deposición de los espíritus violentos, los pactos sociales y políticos y la consecuente revitalización de los derechos fundamentales de la población que han de ser garantizados por el Estado, hacen parte de un accidente histórico que en Colombia se reclama desde hace más de medio siglo: la paz. La oclusión de los factores que han retroalimentado el conflicto interno armado ha comenzado con la dejación de las armas por la guerrilla, pero ello no es la paz. Ella se alcanza con una nueva redistribución del poder, esto es, con un nuevo modelo territorial de Estado con capacidad para producir un nuevo estado de cosas en el que la corrupción, la inequidad y la depredación cedan a procesos virtuosos que garanticen la reconciliación entre los colombianos y entre estos con la naturaleza. El modelo centralista en boga y su principal mecanismo de reproducción, el clientelismo, no lo permiten. Este trabajo se ocupa de allanar el espacio de la utopía posible de un nuevo modelo territorial de Estado basado en los procesos territoriales en curso, siendo el más evidente el de la preeminencia de las zonas metropolitanas sobre el resto de formas de ocupación del territorio $y$, de manera consecuente, la evidente gravitación de amplias zonas del territorio colombiano sobre ellas; es decir, que Colombia es un país de regiones metropolitanas que rebasa la división político-administrativa vigente que, por su parte, es proclive al modelo territorial de Estado centralista.

La argumentación parte de la exposición teórica de las características de un sistema poli-metropolitano que da lugar a la existencia de campos multigravitacionales cuyo reconocimiento es crucial en vista de la proposición de una regionalización basada precisamente en los campos de influencia de las zonas metropolitanas. En la segunda parte se realiza una síntesis crítica de los intentos de regionalización conocidos en Colombia desde el siglo pasado, y en la tercera se concretan algunas de las virtudes de tres modelos de regionalización metropolitana ejemplificantes de los alcances de la modernización del Estado desde los territorios metropolitanos. En la cuarta se expone el modelo de regiones metropolitanas y se realizan sus caracterizaciones, a fin de sustentar la idea de que la promoción del crecimiento regional y los avances en equidad son costos asumibles en aras de un nuevo escenario de distribución del poder proclive a la paz. Estos fenómenos y propuestas se recrean en las reflexiones finales.

\section{La delimitación regional en un espacio poli-metropolitano}

A diferencia de las ciudades-Estado como Singapur, en los países del continente americano es frecuente depararse con la existencia de dos o más zonas metropolitanas de diverso tamaño poblacional, con escalas de aglomeración disímiles y, por tanto, con variadas áreas de influencia: es el polimetropolitanismo (cfr. Alfonso 2014a; 2014b; 2012). En vista del propósito de la construcción de una propuesta de regionalización a partir de la gravitación de los territorios sobre las aglomeraciones que componen un sistema polimetropolitano, hay varios escollos metodológicos que superar. El primero es el de la identificación de las zonas metropolitanas, los núcleos y municipios 
metropolizados, esto es, cuyas poblaciones han establecido vínculos estructurales y coyunturales que tienden a configurarlas como unidad económico-espacial. El segundo consiste precisamente en la delimitación de las áreas de influencia de las zonas metropolitanas; es decir, de la construcción de la propuesta de regionalización. Los métodos gravitacionales comúnmente empleados emplean a lo sumo dos unidades espaciales separadas por un espacio relativamente fácil de diferenciar con el auxilio de ciertas técnicas. Sin embargo, en ámbitos polimetropolitanos lo que es obvio es la existencia de campos multigravitacionales que complejizan el ejercicio de identificación de los umbrales metropolitanos o fronteras de las áreas de influencia de las zonas metropolitanas. Este apartado se ocupa de sugerir la manera de superar estos escollos.

\section{Identificación de las zonas metropolitanas}

¿Sobre qué lugares gravita la vida económica, social y política de un país? La respuesta a esta cuestión es el punto de partida de una propuesta de regionalización. La identificación de tales lugares comienza por la comprensión de la jerarquía poblacional que trasciende a la mera ordenación y asignación de un rango dentro del conjunto del sistema de jurisdicciones locales, pues hay necesidad de verificar si esas ciudades a la cabeza de la jerarquía urbana son a la vez núcleos metropolitanos, esto es, que establecen tal tipo de interacciones con las jurisdicciones localizadas en cierta área en proximidad cuya influencia es creciente y medible. La hipótesis fuerte de inicio es que estos lugares son las zonas metropolitanas $y$, por ende, que estamos en presencia de un país de regiones metropolitanas. El Índice de Metropolización (Jaramillo y Alfonso, 2001, pp. 200-205; Alfonso, 2010, p. 229) es un excelente mecanismo para realizar tal verificación. Se estima la incidencia (I) de las migraciones del núcleo metropolitano sobre el crecimiento poblacional de los municipios de la zona que se construye sobre la base del saldo migratorio:

$$
\mathrm{I}=\frac{\mathrm{NM}_{\mathrm{m}}-\mathrm{m}_{\mathrm{NM}}}{\mathrm{R}_{\mathrm{m}}}
$$

Los nacidos en el núcleo metropolitano que residen en el municipio metropolizado $\left(\mathrm{NM}_{\mathrm{m}}\right)$ conforman un contingente de emigrantes de cuyo número se sustraen los emigrantes en la otra dirección, esto es, los nacidos en el municipio metropolizado que residen en el núcleo metropolitano $\left(\mathrm{m}_{\mathrm{NM}}\right)$, y ese saldo migratorio se divide por el total de residentes en el municipio metropolizado $\left(R_{m}\right)$. Si la razón (I) tiende a cero es que no hay un proceso de expansión metropolitana en curso. En el caso de que lo haya, el paso siguiente consiste en comparar el número efectivo de emigrantes del núcleo metropolitano al municipio metropolizado con el total de residentes en los municipios metropolizados (m) que provienen de la misma zona metropolitana (M), es decir, los nacidos en el núcleo metropolitano que emigraron a $m$ y los nativos de $m$ que residen allí mismo:

$$
\mathrm{A}=\frac{\mathrm{NM}_{\mathrm{m}}}{\mathrm{M}_{\mathrm{m}}}=\frac{\mathrm{NM}_{\mathrm{m}}}{\mathrm{NM}_{\mathrm{m}}+\mathrm{m}_{\mathrm{m}}}
$$


Puesto que se requiere contar con una medida de la unidad espacial en su conjunto que es la zona metropolitana (M), se calcula otra razón cuyo numerador lo componen los nacidos en el núcleo metropolitano que residen en allí mismo (NM) y en los municipios metropolizados $(m)$, mientras que en el denominador se encuentran los nacidos en la zona metropolitana (M) que residen en ella:

$$
\mathrm{B}=\frac{\mathrm{NM}_{\mathrm{M}}}{\mathrm{M}_{\mathrm{M}}}=\frac{\mathrm{NM}_{\mathrm{NM}}+\mathrm{NM}_{\mathrm{m}}}{\mathrm{NM}_{\mathrm{m}}+\mathrm{m}_{\mathrm{NM}, \mathrm{m}}}
$$

El Índice de Metropolización es el cociente de la relación A/B que alcanza el valor de la unidad cuando las distribuciones de nacidos en $N M$ y en $m$ se comportan exactamente igual, y que es inferior a ella cuando el proceso de metropolización de la población no se ha asimilado por completo.

\section{Los campos multigravitacionales} del poli-metropolitanismo

¿Con qué principios se estructura una región metropolitana? Esta es la cuestión central que se planteó Isard (1960, pp. 507-508) como preámbulo al desarrollo de su propuesta de los campos gravitacionales según la cual "las relaciones interregionales pueden concebirse como relaciones entre masas". Desde esta perspectiva teórica, el polimetropolitano entraña la intercalación espacial de más de una masa gravitatoria, situación que se ejemplifica en la Figura 1 en la que, además, se esboza otro de los inconvenientes que con frecuencia enfrentan este tipo de modelos cual es la utilización del ideal euclidiano de la distancia como forma dominante de establecer el umbral $D_{\text {r. }}$ El uso de ese ideal euclidiano de la línea recta entre dos lugares,

Figura 1 - Intercalación de masas gravitatorias en el espacio geográfico y sinuosidad de la distancia en ruta

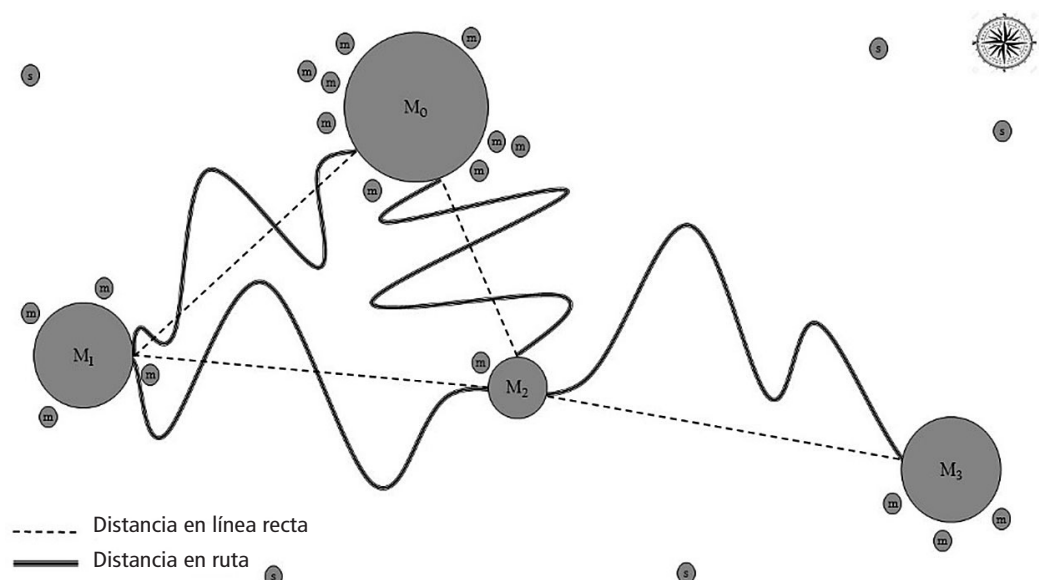

Fuente: el autor. 
o la distancia a "vuelo de pájaro", es muy pertinente en el caso del análisis de planos isomorficos que por causa de la mezquindad de la naturaleza son los más escasos. El interés reduccionista o simplificador del uso de tal ideal no es adecuado en presencia de espacios geográficos con fracturas que alteran las interacciones entre las masas que entran en juego en los campos gravitatorios pues, tal como se representa en la Figura 1, hacen que la distancia en ruta entre tales zonas se aleje significativamente del ideal euclidiano, produciendo un paisaje sinuoso e, inclusive, de rupturas espaciales como la interconexión directa entre $M_{0}$ y $M_{3}$.

Las pequeñas masas denotadas con la letra $m$ representan a los municipios metropolizados, mientras que las marcadas con s son esas jurisdicciones de tamaño muy reducido que se localizan al margen de los campos gravitatorios, conformando zonas apartadas de reducida o nula interacción con el resto del sistema. En los modelos gravitacionales, la función de los municipios metropolizados es la de ensanchar la masa original que es la del núcleo metropolitano tal como se representa en la Figura 2 en la que, además, se elonga la distancia en ruta para compararla con el ideal euclidiano a fin de mostrar la censura que los métodos euclideos realizan sobre una porción considerable de la distancia que efectivamente incide en la gravitación entre núcleos metropolitanos: la distancia en ruta.

Figura 2 - Ensanchamiento de las masas gravitatorias por causa de la metropolización y censura de la distancia efectiva en los modelos que emplean el ideal euclidiano

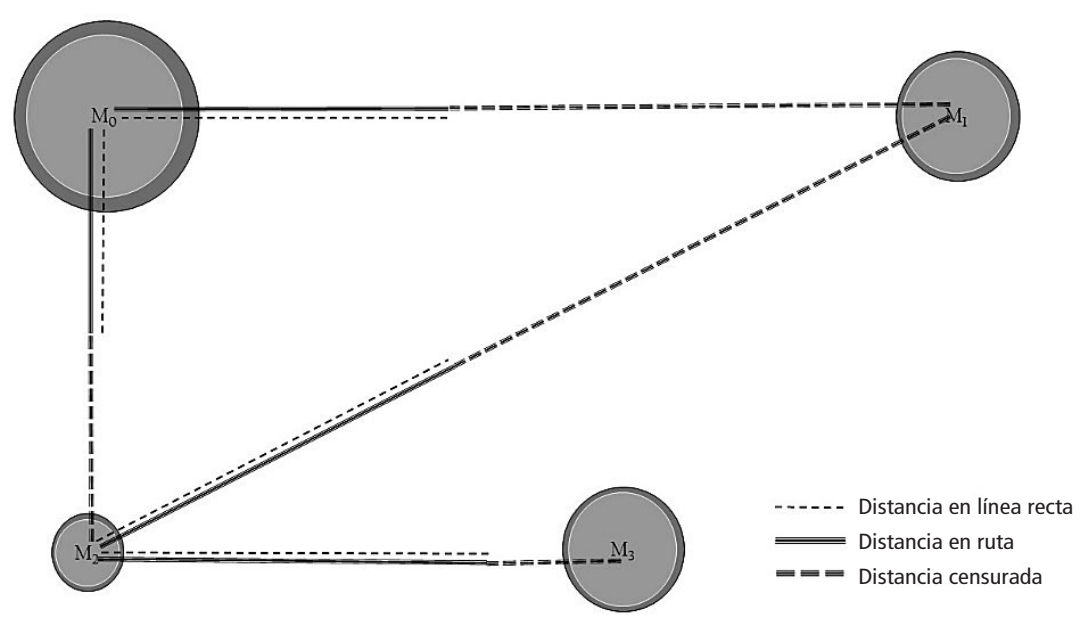

Fuente: el autor. 
Figura 3 - Intersticios espaciales por finitud de los campos gravitatorios de las metrópolis y emergencia de las regiones desarticuladas

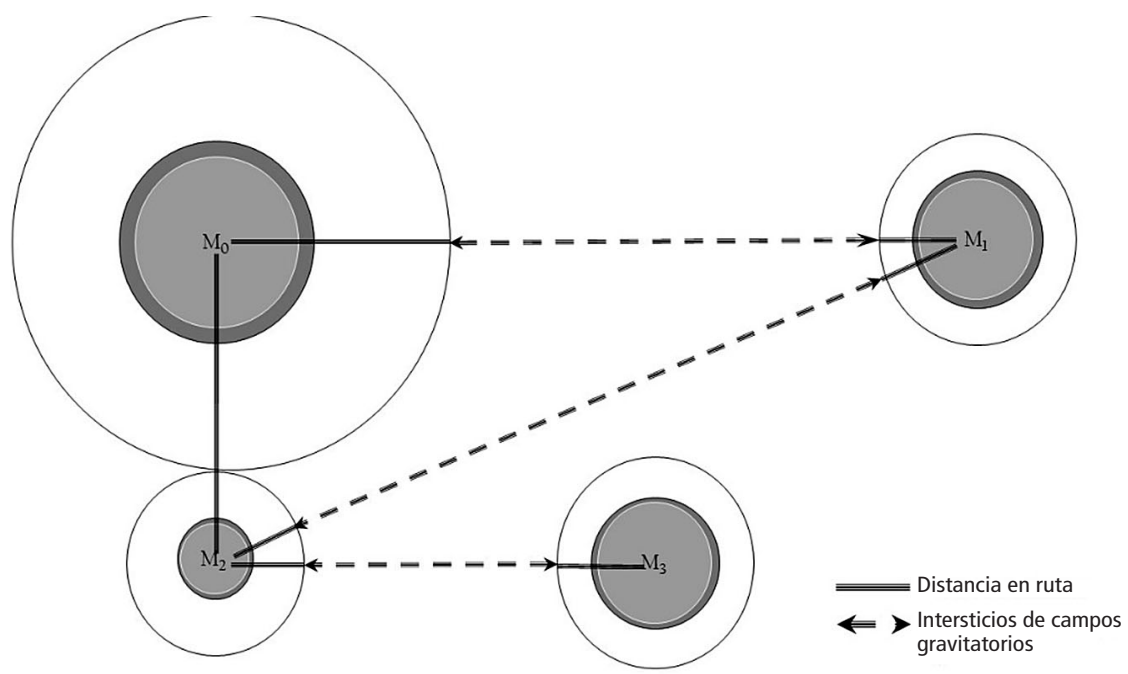

Fuente: el autor.

Tal censura es trascendente pues la finitud de los campos gravitatorios es determinada por la distancia. Algo semejante fue advertido por los físicos en relación con la dispersión de ondas en el espacio dada la curvatura del globo terráqueo. El intersticio denotado en la Figura 3 por la porción discontinúa de la línea que conecta a las metrópolis $M$, es un espacio con el que se ejemplifica la existencia de zonas intersticiales. A diferencia de los modelos de la física que han establecido una constante gravitacional universal, la existencia de estos intersticios es que no existe una constante gravitacional de la misma naturaleza; es decir, que los campos gravitatorios de las metrópolis son finitos y por ello existen umbrales regionales metropolitanos después de los cuales aparecen vastas zonas desarticuladas del sistema urbano-regional.

La distancia en ruta por modo carretero no ha sido empleada en la construcción de algoritmos debido probablemente a la indisponibilidad de recursos tecnológicos para hacerlo. El desarrollo de la tecnología informática y de los procesos satelitales de teledetección ha facilitado el procesamiento geoespacial y hoy por hoy es posible superar esta dificultad de manera ágil y con confiabilidad y, con ello, contar con otras medidas de auxilio para los estudios geográficos. Una muy sencilla se refiere al Índice de Sinuosidad (IS) que intuitivamente capta el planteamiento de la Figura 1:

$$
I S=\frac{D r}{D e}
$$


Donde $D r$ es la distancia en ruta y $D e$ es la distancia euclidea. Si la primera coincide con la segunda, el cociente es la unidad pues se habría alcanzado el ideal euclidiano, que es sintomático de una situación en la que la infraestructura vial habrá facilitado la minimización de los costos de transporte entre los dos puntos concernidos en el análisis. Los decimales que excedan a la unidad indican el porcentaje de la desviación sobre tal ideal $y$, por tanto, el grado en el que se agudiza la fricción a la que Prager y Thisse (2010) han denominado como "la tiranía de la distancia".

La pertinencia analítica de las distancias en ruta obedece a que, como se ha argumentado, la sinuosidad de la red vial principal incide de manera decisiva en la finitud de los campos gravitatorios. La sinuosidad se asocia positivamente a los costos de transporte, de personas y mercancías, existiendo diferencias notables entre países tanto por el heteromorfismo de su geografía como por la manera como se ha gestionado el desarrollo vial. La Tabla 1 ilustra esta idea. Se escogieron las cinco primeras ciudades en la jerarquía poblacional de cada país del continente americano y se calcularon los índices en relación con las distancias a la primera ciudad: el IS2 es el índice de sinuosidad entre la primera y la segunda, el IS3 entre la primera y las dos siguientes, el IS4 entre la primera y las tres siguientes y el IS5 entre la primera y las cinco siguientes. Adicionalmente, se agruparon por escalas de acuerdo con la tasa de urbanización reciente. En los tres primeros grupos, el promedio de la sinuosidad en todos los casos se incrementa cuando se desciende en la escala de la urbanización, y en los dos últimos grupos se desvanece esta regularidad.
Si bien Colombia es el segundo país en urbanización entre los del grupo con urbanización elevada, la sinuosidad de su sistema vial principal es la segunda más elevada del continente. Un índice de sinuosidad próximo a la unidad es sintomático de la aproximación del sistema vial al ideal euclidiano y, por oposición, es esperable que la distancia en ruta altere los campos gravitatorios de las zonas metropolitanas de manera más intensa cuanto más elevada sea la sinuosidad. Este último es lo que ocurre en Colombia. Entre el Archipiélago de San Andrés y Providencia y el país continental, las interacciones económicas y poblacionales no son tan intensas como para afectar el ejercicio de regionalización propuesto. El 56\% del territorio colombiano se halla desarticulado de las dinámicas del desarrollo que tienen lugar en las zonas metropolitanas - ver Figura 4 -, fenómeno que encarna varias contradicciones, siendo la más relevante que mientras los bosques húmedos de la zona selvática del Amazonas y buena parte de la Orinoquia deberán ser conservados, el andén medio y el alto del pacífico, la parte norte del Cauca y casi la totalidad del Chocó, así como la Alta Guajira, acogen un contingente de población desatendido por el Estado y, por tanto, allí la recurrencia de la muerte por causa de la inanición y la gastroenteritis, los paros cívicos y de la acción de grupos ilegales es perenne. Otro tanto ocurre en la región nor-oriental de la Orinoquia en donde casi la totalidad de los municipios araucanos sostienen más interrelaciones con sus vecinos próximos de Venezuela que con los colombianos. 
Tabla 1 - Urbanización e índices de sinuosidad de la red vial en algunos países del continente americano

\begin{tabular}{|c|c|c|c|c|c|c|}
\hline \multirow[b]{2}{*}{ País } & \multicolumn{2}{|c|}{ Urbanización } & \multicolumn{4}{|c|}{ Índices de Sinuosidad } \\
\hline & Grupo & $\begin{array}{c}\text { Tasa de } \\
\text { Urbanización }\end{array}$ & IS2 & IS3 & IS4 & IS5 \\
\hline Uruguay & \multirow{7}{*}{ Muy elevada } & 93,0 & 1,16 & 1,14 & 1,13 & 1,13 \\
\hline Argentina & & 92,0 & 1,08 & 1,07 & 1,15 & 1,15 \\
\hline Venezuela & & 89,1 & 1,39 & 1,43 & 1,42 & 1,41 \\
\hline Chile & & 87,8 & 1,26 & 1,26 & 1,25 & 1,24 \\
\hline Brasil & & 85,2 & 1,21 & 1,32 & 1,28 & 1,27 \\
\hline Canadá & & 81,0 & 1,07 & 1,27 & 1,27 & 1,27 \\
\hline Estados Unidos & & 80,7 & 1,14 & 1,13 & 1,14 & 1,14 \\
\hline Puerto Rico & \multirow{7}{*}{ Elevada } & 78,5 & 1,55 & 1,31 & 1,50 & 1,44 \\
\hline Colombia & & 77,6 & 1,80 & 1,65 & 1,49 & 1,52 \\
\hline Cuba & & 77,3 & 1,14 & 1,12 & 1,11 & 1,11 \\
\hline México & & 76,7 & 1,30 & 1,38 & 1,29 & 1,25 \\
\hline Perú & & 76,3 & 1,33 & 1,33 & 1,25 & 1,21 \\
\hline Ecuador & & 73,1 & 1,58 & 1,57 & 1,44 & 1,46 \\
\hline República Dominicana & & 70,5 & 1,06 & 1,10 & 1,12 & 1,18 \\
\hline Bolivia & \multirow{4}{*}{ Media } & 67,8 & 1,62 & 1,76 & 1,75 & 1,75 \\
\hline Paraguay & & 62,3 & 1,09 & 1,09 & 1,10 & 1,10 \\
\hline Honduras & & 61,2 & 1,35 & 1,38 & 1,61 & 1,66 \\
\hline Nicaragua & & 60,3 & 1,91 & 1,68 & 1,60 & 1,44 \\
\hline Panamá & \multirow{3}{*}{ Baja } & 59,6 & 1,30 & 1,29 & 1,37 & 1,38 \\
\hline Costa Rica & & 51,2 & 1,38 & 1,38 & 1,46 & 1,36 \\
\hline El Salvador & & 51,0 & 1,14 & 1,37 & 1,26 & 1,26 \\
\hline Guatemala & \multirow{2}{*}{ Rural } & 43,5 & 1,25 & 1,16 & 1,19 & 1,33 \\
\hline Haiti & & 42,3 & 1,18 & 1,27 & 1,23 & 0,12 \\
\hline
\end{tabular}

Fuente: Cálculos con base en www.lasdistancias.com e indicadores de la CEPAL y del Bureau de Población de los Estados Unidos.

\section{La delimitación de las regiones metropolitanas}

Los campos multigravitacionales de las metrópolis operan, como se ilustró en la Figura 1, de manera diferenciada dependiendo de la geografía. Hay zonas que se encuentran de manera exclusiva en el campo gravitatorio de una metrópoli, pero hay las que potencialmente pueden estar en dos o más; claro, si se consideran por separado. Los traslapes de los campos gravitatorios son improcedentes en razón de las masas y distancias que entran en juego cuando se consideran tres o más 
de éstos. Establecer la frontera de un campo gravitatorio es equivalente a delimitar la región de influencia de la zona metropolitana y, para ello, un método pertinente es sugerido por Reilly (1931) en los modelos gravitaciones del comercio, en los que el límite regional buscado $\left(D_{1}\right)$ en la ecuación (5) se deduce con sólo conocer la distancia en ruta Drentre dos zonas "a" y "b" y la población de cada una de ellas:

$$
D_{l}=\frac{D_{r}}{1-\sqrt{\frac{P_{b}}{P_{a}}}}
$$

Algunas variantes se le han hecho desde entonces como las que se introducen en los anuarios comerciales de España, en las que la población es sustituida por el tamaño de los equipamientos comerciales de las ciudades, con la precaución de las variables que se sustituyen guarden la relación de masas prevista para que opere la ecuación (5). La distancia en ruta es igualmente sustituible por los valores típicos de tiempo de viaje (Chasco, 2000, p. 5). Cuando se adopta la población para establecer el umbral del área de mercado se asume que la demanda es una buena medida de ella, pudiéndose afinar la medición incorporando alguna corrección con base en los ingresos de las poblaciones consideradas. En el segundo caso, las áreas de los establecimientos comerciales son una expresión de la oferta. En situaciones en las que existan reconocidas diferencias en la productividad de los recursos localizados en las diferentes zonas, lo más conveniente es recurrir a indicadores de oferta.

\section{Caracterización de las regiones metropolitanas}

No obstante que sobre las zonas metropolitanas gravitan considerables porciones del territorio nacional y de las jurisdicciones municipales en que ha sido fragmentado, tanto como para que sobre tal gravitación sea factible establecer los umbrales espaciales que delimitan las regiones metropolitanas, ello no significa que con ello se haya conseguido identificar algún tipo de característica homogeneizante; por el contrario, la heterogeneidad estructural del territorio persiste como regla para la organización de regiones tan diversas como las metropolitanas. Si una región fuese homogénea no tendría mayor sentido caracterizarla, como si se requiere en el caso de las regiones metropolitanas. No hay unicidad de criterios para hacer tal caracterización. La subregionalización con los mismos criterios gravitatorios es una opción comúnmente empleada en los anuarios de comercio, otras recurren a criterios estáticos del tamaño de la población mientras que la especialización productiva lo es en los enfoques de la competitividad regional, por ejemplo.

El interés por comprender las dinámicas de ocupación y desocupación de los territorios remite en principio a la cuestión poblacional. Desde tal perspectiva, una buena aproximación es la de los ciclos del desarrollo urbano que, además, es factible de replicar para los del desarrollo rural. En la etapa de la urbanización, la población y la actividad económica se concentran en los centros urbanos. En la fase de la 
suburbanización el crecimiento de las áreas suburbanas supera la de la ciudad central y, finalmente, se asiste a un desplazamiento de la población y de los puestos de trabajo en tales áreas. En el ciclo de desurbanización ciertos lugares comienzan a perder población, a medida que comienzan a desarrollarse pequeños centros urbanos autónomos y el sistema urbano en su conjunto se vuelve menos polarizado. En el período de la reurbanización, las ciudades centrales que perdieron población comienzan a crecer nuevamente (Comisión de las Comunidades Europeas, 1992; Piperno, Piazza y Pola, 2014). Un punto de vista complementario al de los ciclos del desarrollo es el de la ecología. La inestabilidad de los sistemas socio-ecológicos obedece a su simplicidad (Hoenigsberg, 1977, p. 14) o, en el mismo sentido, su complejidad entraña estabilidad debido a la posibilidad de que se produzcan las compensaciones necesarias para dar vitalidad a algún hábitat. La monotonía de los primeros contrasta con la variedad de los segundos, siendo estos sistemas territoriales complejos el ideal tipo de la ocupación por cuanto en ellos existen mecanismos de compensación de diferente naturaleza que facilitan la compatibilidad y coexistencia de los modos de vida urbana y rural.

Una síntesis de estas ideas complementarias es la taxonomía de la Tabla 2. Son sistemas robustos aquellos en el que el crecimiento poblacional urbano y rural ocurre simultáneamente y ello ocurre porque se complejizan y complementan ambos ambientes. Puede ocurrir que en un sistema el crecimiento poblacional urbano se acompañe del decrecimiento poblacional rural, es decir, que conviven dinámicas de complejización urbana con simplificación rural, dando lugar a la ausencia de complementariedades y posibilidad de compensaciones socio-ecológicas, sistema al que se denomina urbano endeble. Cuando el fenómeno se yuxtapone, esto es, simplificación urbana y complejización rural, el sistema es rural endeble. Y, por último, la simplificación simultánea de los dos ambientes da lugar a un sistema frágil.

Tabla 2 - Taxonomías territoriales a partir de las dinámicas poblacionales

\begin{tabular}{l|c|c|c}
\hline \multirow{2}{*}{ Dinámicas poblacionales por zonas } & \multicolumn{2}{c}{ Rurales } \\
\cline { 3 - 4 } & Poblamiento & Poblamiento & Despoblamiento \\
\hline \multirow{2}{*}{ Urbanas } & Despoblamiento & Robustos & Urbano Endeble \\
\cline { 2 - 4 } & Rural Endeble \\
\hline
\end{tabular}

Fuente: el autor. 
Cada una de estas dinámicas poblacionales entraña al menos tres movimientos - el crecimiento, el decrecimiento y la recuperación - con las que es posible desagregar la matriz de en 36 subsistemas socio-ecológicos. Esta desagregación ofrece nuevas posibilidades analíticas tales como la identificación de fenómenos como la suburbanización de una porción de la población y su trascendencia para el conjunto del país y de las regiones metropolitanas, como también la detección de un auge repentino de ciudades intermedias del que se pueda esperar una modificación de trascendencia de su estructura urbano-regional, entre otras.

\section{Breve historia de las regionalizaciones en Colombia}

La trascendencia política de la regionalización de un país depende de los propósitos que persiga y de la anuencia de la sociedad y el Estado para introducir las modificaciones del orden en curso que se busque alterar, aunque también hay regionalizaciones para reafirmar el orden en curso. Y están los ejercicios académicos que por subvertir el orden en curso son deliberadamente ignoradas por los aparatos de Estado así como por las fracciones conservadoras de la sociedad alarmadas por la potencial modificación del statuo quo.

Las jurisdicciones municipales, provinciales, distritales o departamentales tienen sentido político en tanto sus roles como integrantes de un modelo territorial de Estado, fenómeno cuya comprensión se inserta en la historia de los hechos políticos y de las visiones de sus protagonistas sobre la administración del territorio nacional. La delimitación actual del territorio colombiano data de 1934 cuando, con el fin de la guerra con Perú precedido por la definición de los linderos con Brasil en 1928 y con Panamá en 1924, concluyeron tres litigios fronterizos vigentes por entonces. Porciones considerables del territorio colombiano organizado por los conquistadores y reafirmado durante la Colonia fue cercenado (Esquivel, 2003, pp. 177-187). La delimitación de los virreinatos que realizó la corona española no guarda relación alguna con la organización políticoadministrativa la de 1934 cuando consistía en catorce departamentos, tres intendencias y siete comisarías. Esta modalidad tuvo como antecedentes a las provincias y fue el precedente de la actual organización introducida por la Constitución Política de 1991 que consiste en 32 departamentos y el Distrito Capital, fragmentados jurisdiccionalmente en 20 corregimientos departamentales y 1.102 municipios.

El Departamento Nacional de Planeación - DNP - divulgó hacia 1976 una regionalización con la que pretendía impulsar el proceso de descentralización, consistente en seis regiones de las que la denominada "región central" abarcaba más de la mitad del país, pues de ella formarían parte tanto los departamentos ubicados en la cordillera oriental como los de las regiones orinoquense y amazónica. Este ejercicio tuvo como precedentes las regionalizaciones construidas por Guhl y Fornaguera en 1969 con el criterio del epicentrismo regional, y la consignada en el Informe Lebret y construida a partir de las 
condiciones diferenciadas del desarrollo en 1956. En 1984 una nueva regionalización del DNP estableció cinco regiones de planificación que se popularizaron con el nombre de Consejos Regionales de Planificación Económica y Social, entidades adscritas al Departamento y con presupuestos cuya asignación y ejecución eran controladas por el Ministerio de Hacienda. La idea de las regiones administrativas y de planificación cobró fuerza desde entonces y fue Fals Borda quien en hacia 1996 presentó una propuesta consistente en ocho de estas que, además, se introdujeron en la Constitución Política de 1991 (cfr. Sarmiento y Castillo, 1998).

La Fundación Social (1998) realizó un conjunto de regionalizaciones en una coyuntura decisiva para el ordenamiento territorial marcada por la promulgación de la Ley de Desarrollo Territorial o Ley 388 de 1997. Por su parte, Molina y Moreno (2001) propusieron otra regionalización a partir de una medida de funcionalidad a la que denominaron el Índice Acumulado Urbano. Ninguna de estas logró realizar el potencial transformador que pretendían.

Las recurrentes anomalías en los componentes del clima asociadas al fenómeno secular del cambio climático, han inspirado la realización de varios ejercicios de regionalización ambiental con metodologías como las de Caldas-Lang de la que resultan 28 tipos de ambiente, la de Lang con seis, la de Holdridge con 26 y la de Martone con seis (Ideam, 2011). Snow (1976) empleó el criterio de las equiprecipitaciones en la geografía física para identificar la existencia de veinte regímenes pluviométricos, controlados además por la variación gradual de las latitudes.

\section{Las regiones metropolitanas en los intentos de modernización del Estado}

Los modelos de territoriales de Estado centralistas concentran el poder decisorio en el nivel central de gobierno y otorgan autonomías restringidas a los entes territoriales subnacionales que, en tales contextos, asumen el rol de ejecutores locales de programas nacionales. Las transferencias de recursos del presupuesto nacional a los entes territoriales inciden negativamente en el desarrollo local al propiciar el desmedro de las fuentes locales de financiación del desarrollo y la reiteración y sofisticación de las diferentes formas de corrupción administrativa, entre las que el saqueo al erario aparece como la más conspicua de ellas. Esta institucionalidad perversa se erige como un statuo quo en el que sus participantes gozan de poderosos incentivos para custodiarla. Las elites que controlan el nivel central de gobierno saben que controlando las metrópolis controlan el país. Los gobernantes locales de los municipios metropolizados sostienen que un gobierno metropolitano restringe sus autonomías a asuntos poco significativos que, de hecho, lo son pero por el centralismo. Es por estas razones que la posibilidad de configurar zonas metropolitanas, con órbitas funcionales supralocales y responsabilidades políticas, es repudiada tanto por los niveles centrales de gobierno como por los gobernantes locales porque ellas entrañan la emergencia de un poderoso contrapoder (Lefèvre, 2014, p. 32) con la potencia necesaria como para alterar el statuo quo. 
La modernización del Estado desde los territorios significa precisamente modificar el statuo quo para dar paso a un modelo virtuoso en el que se desarrollen auténticas autonomías en función del alcance de fines como la aceleración del desarrollo local, el cierre de las brechas socio-espaciales y la ocupación que promueva la consolidación de relaciones preservadoras entre la sociedad y la naturaleza. Es factible el alcance de tales fines a partir de lo existente, esto es, de las zonas metropolitanas con reconocido dinamismo poblacional y económico que serían el soporte indiscutible de un nuevo orden territorial basado en ellas, las regiones metropolitanas.

Lefèvre (2014, pp. 66-68) sostiene la idea de la existencia de instituciones metropolitanas fuertes y débiles. Estas últimas abundan. Dentro de las primeras el caso paradigmático en la Comunidad Autónoma de Madrid - CAM que, habiendo surgido a costa de la precedente estructura provincial madridista, se ha erigido como el auténtico poder metropolitano que le otorga cierta semblanza federalista al Estado español, al menos en esta escala territorial. La CAM la conforman 179 municipios en donde se ejecuta un cuantioso presupuesto que equivale a cinco presupuestos de la capital, Madrid. Las autonomías de la CAM no se limitan a la ejecución de proyectos de inversión públicos 0 a la organización del territorio, tareas de por sí muy relevantes, pues también tiene potestad en materia legislativa y regulatoria en sus órbitas funcionales.

El statuo quo territorial ha comenzado a dar un giro en Francia desde la promulgación de la ley 2014-58 de 2014, o ley de Modernización de la Acción Pública Territorial y la Afirmación de las Metrópolis -
MAPTAM. Diversas contribuciones académicas antecedieron a esta decisión, ambientaron los debates y aportaron ideas a su contenido. Los análisis de Hugounenq, Le Cacheux y Madiès (1999) permitieron advertir sobre los riesgos de pérdida de soberanía fiscal y el constreñimiento de los presupuestos públicos como resultado de la competencia por localizaciones industriales por la vía de la desgravación impositiva en las zonas metropolitanas, mientras que Madiès (1997, 2006) identificó la intercomunalidad asociativa, la federativa y la solidaria como alternativas para inducir una conducta cooperativa para abolir la "guerra tarifaria" entre las jurisdicciones metropolizadas. Principios de cooperación como los de la solidaridad financiera intermunicipal y de organización regional como el de la geometría variable fueron retomados por el Sindicato París Métropole (2012, p. 58).

Las normas consignadas en el título primero se orientan a clarificar las competencias de las entidades territoriales y a promover mecanismos de coordinación entre ellas. En el tercer artículo se destaca que las regiones lideran lo relativo a la planificación y el desarrollo sostenible del territorio, la protección de la biodiversidad, el desarrollo económico, el apoyo a la innovación, la internacionalización de las empresas, la intermodalidad y complementariedad entre modos de transporte, y el apoyo a la educación superior y la investigación. A los departamentos les corresponde organizar la acción social, el desarrollo social y la contribución a la reducción de la pobreza energética, la autonomía de las personas y la solidaridad territorial. A las comunas y a los Establecimientos Públicos de Cooperación Intercomunal - EPCI - les 
compete gestionar con sus propios recursos la movilidad sostenible, la organización de los servicios públicos locales, la ordenación del territorio y el desarrollo local. Hacen parte de este título un conjunto de medidas complementarias orientadas a organización plural de los consejos regionales, a la organización de autoridades únicas del transporte regional y a la racionalización de la acción pública territorial.

En el segundo título se dictan las normas tendientes a la afirmación de las metrópolis. De las normas específicas para la zona metropolitana de Ile de France como núcleo de las Región Metropolitana Gran París, para Lyon y Aix-Marselle-Provence, así como para las previstas en los artículos 43 a 53 - Burdeos, Grenoble, Lille, Nantes, Niza, Rennes, Rouen, Estrasburgo y Tolouse - se destaca la estrategia de la fiscalidad propia de los EPCl; esto es, de la autonomía en el recaudo del gravamen de la tasa profesional, la principal fuente de recursos impositivos en Francia. Aspectos particulares como la creación de la misión para la anticipación de los posibles conflictos en la RM Gran París son novedosos pues a ella se le encargó preparar las condiciones jurídicas y presupuestales para la creación de la $\mathrm{EPCl}$, entre las que es resaltable el pacto fiscal y financiero de los entes territoriales que allí participan. De la composición plural de la misión participan representantes de los alcaldes, presidentes de los consejos, de las $\mathrm{EPCl}$ ya en funcionamiento, del sindicato mixto París Métropole y de representantes de otras organizaciones de derecho público y privado de la RM Gran París. El artículo 59 establece que los consejos generales, regionales y las demás entidades de derecho público creadas por la
MAPTAM comenzaran a ejercer sus funciones antes del $1^{\circ}$ de enero de 2020. La ley 2015-991 reglamentó este artículo y en ella sobresalen por su novedad las normas consignadas en el título tres que se refieren a la solidaridad e igualdad de los territorios.

De las reformas territoriales recientes una de las más notables es la de la Constitución Política de la Ciudad de México, promulgada a partir de la publicación de su texto en la Gaceta Oficial el 5 de febrero de 2017. Del preámbulo cabe resaltar la exaltación a que este nuevo orden es posible gracias "la organización cívica y autónoma de sus pobladores y la resistencia histórica contra la opresión. Es la culminación de una transición política de inspiración plural y democrática". En esta dirección, el numeral $4^{\circ}$ del artículo $1^{\circ}$ precisa que "La Ciudad es libre y autónoma en todo lo concerniente a su régimen interior y a su organización política y administrativa". Diferentes modalidades de ciudad se traslapan para establecer las garantías y la progresividad de los derechos: ciudad garantista, de libertades y derechos, democrática, educadora y del conocimiento, solidaria, productiva, incluyente, habitable y segura; por su parte, el artículo 20 perfila a la ciudad global. Especial interés dedica el nuevo orden a la coordinación metropolitana y regional al dedicarle el artículo 19 consistente en siete numerales dedicados a la coordinación de políticas y gestión del desarrollo con las demás jurisdicciones del Valle de México y la Región Central. En particular, el numeral quinto determina que "el Cabildo impulsará ante el Consejo de Desarrollo Metropolitano y los organismos correspondientes los mecanismos de coordinación metropolitana y regional que especifiquen los objetivos, 
plazos, términos, recursos y responsables para la ejecución, seguimiento y evaluación de las acciones y programas acordados, así como de participación y representación ciudadana en los mismos".

\section{Las regiones metropolitanas de Colombia: gravitación y desarticulación}

Una de las razones para que el statuo quo territorial perdure es la ausencia de propuestas alternativas de reorganización del modelo territorial de Estado, ausencia que obedece al desinterés activo de la porción de la sociedad cooptada por el mismo, y al desinterés pasivo de los creyentes en que tal estado de cosas es el resultado de una elección pública y que, por tanto, es así porque debe serlo. La siguiente es una propuesta alternativa que, soportada en los argumentos teóricos, metodológicos y políticos esbozados hasta el momento, pretende propiciar un debate inaplazable en vista de la transición hacia la paz que exige de la modernización del Estado desde los territorios. Con las ecuaciones (1) a (3) se han identificado las zonas metropolitanas a partir de los resultados del último Censo de Población realizado en 2005 (cfr. Alfonso, 2010; 2012; 2014a). Ante la ausencia de la actualización del Censo que debió ocurrir en el marco de la ronda de censos del 2010 de América Latina y Caribe, se han realizado algunos ajustes a partir de la verificación de estadísticas complementarias como las de la producción inmobiliaria $y$, adicionalmente, de inspecciones sobre el terreno. De manera complementaria, los criterios de la taxonomía de la Tabla 2 permitieron complementar la jerarquía espacial que se presenta en la Tabla 3.

Las nueve zonas metropolitanas y los 68 municipios metropolizados son de diferente envergadura, al decir de sus considerables diferencias de tamaño poblacional. En ellas residía el $46,2 \%$ de la población colombiana en el 2005 , mientras que el $53,8 \%$ restante lo hacía en las 1.045 jurisdicciones restantes. Dos aspectos adicionales merecen ser resaltados. 375 jurisdicciones municipales son endebles o frágiles y allí residen algo más de cinco millones de personas, el $12 \%$ de la población del país, de donde es esperable que provenga el mayor contingente de migrantes internos. Por su parte, las zonas metropolitanas del Eje Cafetero - Pereira, Manizales y Armenia atraviesan por una transición demográfica y económica originada en la crisis del modelo gremio-Estado que por décadas se erigió sobre la base de las divisas de la exportación de café. Por su proximidad, en adelante se consideraran como una unidad especial metropolitana.

\section{Efectos fiscales de las relaciones centralistas y corrupción administrativa}

La división político-administrativa de Colombia es el soporte administrativo del modelo territorial de Estado centralista-clientelista. El nivel central de gobierno transfiere recursos ordinarios y de capital a los entes territoriales, departamentos y municipios, y las partidas regionales en el presupuesto nacional son destinadas a proyectos de inversión estratégicos para la reproducción de los grupos 
Tabla 3 - Las zonas metropolitanas en la jerarquía espacial y la población de Colombia en 2005

\begin{tabular}{|c|c|c|c|c|c|}
\hline \multirow{2}{*}{$\begin{array}{l}\text { Jerarquía } \\
\text { Espacial }\end{array}$} & \multicolumn{2}{|r|}{ Jurisdicciones } & \multicolumn{3}{|c|}{ Población } \\
\hline & $\begin{array}{c}\text { Núcleo } \\
\text { Metropolitano }\end{array}$ & Municipios Metropolizados & $\begin{array}{c}\text { Núcleo } \\
\text { Metropolitano }\end{array}$ & $\begin{array}{c}\text { Municipios } \\
\text { Metropolizados }\end{array}$ & Total \\
\hline \multirow{9}{*}{ 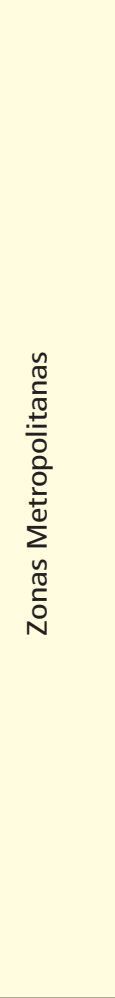 } & Bogotá & $\begin{array}{l}\text { Bojacá, Cajicá, Cota, Chía, El Rosal, } \\
\text { Facatativá, Funza, Fusagasugá, } \\
\text { Gachancipá, La Calera, Madrid, } \\
\text { Mosquera, Sibaté, Soacha, } \\
\text { Sopó, Subachoque, Tabio, Tenjo, } \\
\text { Tocancipá, Zipaquirá, Silvania, } \\
\text { Choachí, Cogua y Suesca }\end{array}$ & 6.840 .116 & 1.328 .435 & 8.168 .551 \\
\hline & Valle de Aburrá & $\begin{array}{l}\text { Barbosa, Bello, Caldas, Copacabana, } \\
\text { Envigado, Girardota, Itagüí, La Ceja, } \\
\text { La Estrella, Marinilla, Rionegro, } \\
\text { Sabaneta, Guarne y El Retiro }\end{array}$ & 2.214 .494 & 1.363 .769 & 3.578 .263 \\
\hline & Cali & $\begin{array}{l}\text { Candelaria, Jamundí, Palmira y } \\
\text { Yumbo }\end{array}$ & 2.119 .843 & 543.649 & 2.663 .492 \\
\hline & Barranquilla & $\begin{array}{l}\text { Galapa, Malambo, Puerto Colombia } \\
\text { y Soledad }\end{array}$ & 1.146 .498 & 622.693 & 1.769.191 \\
\hline & Bucaramanga & $\begin{array}{l}\text { Floridablanca, Girón, Piedecuesta y } \\
\text { Lebrija }\end{array}$ & 516.460 & 538.845 & 1.055 .305 \\
\hline & Cúcuta & $\begin{array}{l}\text { El Zulia, Los Patios, San Cayetano y } \\
\text { Villa del Rosario }\end{array}$ & 587.567 & 161.889 & 749.456 \\
\hline & Pereira & $\begin{array}{l}\text { Dosquebradas, La Virginia, Santa } \\
\text { Rosa de Cabal y Cartago }\end{array}$ & 443.442 & 405.340 & 848.782 \\
\hline & Manizales & $\begin{array}{l}\text { Chinchiná, Neira, Villamaría y } \\
\text { Palestina }\end{array}$ & 379.794 & 146.008 & 525.802 \\
\hline & Armenia & $\begin{array}{l}\text { Calarcá, La Tebaida, Circasia y } \\
\text { Montenegro }\end{array}$ & 280.881 & 174.535 & 455.416 \\
\hline \multirow{4}{*}{ 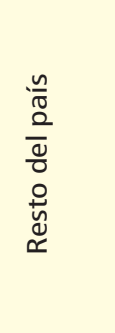 } & $\begin{array}{l}\text { Crecimiento } \\
\text { Robusto }\end{array}$ & 670 & & & 17.928 .575 \\
\hline & $\begin{array}{l}\text { Crecimiento } \\
\text { Urbano Endeble }\end{array}$ & 151 & & & 2.915 .667 \\
\hline & $\begin{array}{l}\text { Crecimiento Rural } \\
\text { Endeble }\end{array}$ & 200 & & & 1.944 .027 \\
\hline & $\begin{array}{l}\text { Crecimiento } \\
\text { Frágil }\end{array}$ & 24 & & & 286.065 \\
\hline & Total & 1.122 & & & 42.888 .592 \\
\hline
\end{tabular}

Fuente: Cálculos con base en estadísticas censales del Dane-Departamento Administrativo Nacional de Estadística. 
en el poder. El cambio del respaldo de los políticos en el Congreso por participación de sus lugares de origen en las partidas regionales y en el esquema general de transferencias, es un patrón de conducta que necesariamente se reproduce a escala local en donde la estrategia electorera se basa en la compra de votos a cambio de beneficios particulares pagaderos con recursos públicos; es decir, que la corrupción es endógena al modelo territorial de Estado centralista-clientelista.

Las actuales reglas del Sistema Intergubernamental de Transferencias se establecieron mediante el Acto Legislativo 001 de 2001 que después tomo cuerpo en la Ley 715 de 2001, habiéndose establecido desde entonces el Sistema General de Participaciones bajo el pretexto de la reducción de las brechas fiscales de los municipios o de nivelación de la capacidad fiscal y, coetáneamente, de la necesidad de la armonización fiscal de los servicios de educación y de salud mediante las transferencias condicionadas de acuerdo con los estándares alcanzados en su provisión. La reforma no se ha traducido en una transformación de fondo en la estructura de financiamiento de las jurisdicciones municipales y, por el contrario, la dependencia de los recursos del nivel central - transferencias ordinarias y de capital, regalías mineras y cofinanciaciones - permanece estable en la totalidad de jurisdicciones $y$, en algunos casos, llega a incrementarse. El centralismo fiscal es evidente a la luz de los resultados de la Tabla 4 en donde, además, es evidente el escalamiento de la dependencia fiscal del centro que se

Tabla 4 - Participación (\%) de las transferencias corrientes y de capital, regalías mineras y cofinanciación del nivel central de gobierno en los ingresos totales de los municipios antes de financiamiento, Colombia 2000-2014

\begin{tabular}{l|c|c|c|c}
\hline \multirow{2}{*}{ Jerarquía Espacial } & \multicolumn{3}{c}{ Administración } \\
\cline { 2 - 5 } & Pastrana & Uribe I & Uribe II & Santos I \\
\hline Zonas Metropolitanas & 18,1 & 26,0 & 26,0 & 24,9 \\
Núcleos Metropolitanos & 17,0 & 24,5 & 24,2 & 22,7 \\
Municipios Metropolizados Próximos & 23,9 & 33,7 & 33,9 & 33,5 \\
Municipios Metropolizados Lejanos & 30,8 & 31,3 & 33,6 & 35,8 \\
\hline Resto del País & 35,5 & 45,3 & 45,2 & 44,3 \\
Crecimiento Robusto & 34,9 & 45,1 & 44,8 & 44,0 \\
Crecimiento Urbano Endeble & 36,0 & 44,7 & 45,5 & 44,5 \\
Crecimiento Rural Endeble & 38,5 & 47,5 & 48,4 & 47,0 \\
Crecimiento Frágil & 40,7 & 50,0 & 49,6 & 49,3 \\
\hline Total & 27,2 & 35,6 & 35,9 & 35,4 \\
\hline
\end{tabular}

Fuente: Cálculos con base en estadísticas del DNP-Departamento Nacional de Planeación. 
incrementa a medida que se desciende en la jerarquía espacial, con independencia de las posibles diferencias ideológicas de las administraciones de turno. Es decir, el centralismo es un proyecto de Estado.

La regresividad del centralismo fiscal en cuanto a los propósitos del avance en la autonomía fiscal de los entes territoriales se capta a través de la monotonía del esfuerzo tributario local que se plasma en los resultados de la Tabla 5. Las diferencias de acuerdo con la jerarquía espacial son evidentes. Las bases tributarias locales mejor dotadas y los mecanismos de recaudo más eficaces están en las zonas metropolitanas, mientras que en el resto del país hay una homogeneización perniciosa inducida por las transferencias del nivel central de gobierno. Esta medida del esfuerzo tributario local es crucial para el análisis de un nuevo modelo territorial de Estado, pues indica el statuo quo fiscal o punto de partida de un nuevo modelo basado en el dinamismo de una auténtica autonomía local.

El contexto es el de una estrategia centralista como proyecto de Estado orientada al control de los territorios con el uso de instrumentos fiscales. Como los resultados de las zonas metropolitanas indican que éstas han adquirido más autonomía, es evidente que ellas se erigen como un potencial contrapoder al centralismo. La corrupción administrativa ocurre en regímenes federalistas como centralistas. Modelos territoriales centralistas que no recurren al clientelismo al menos de

Tabla 5 - Esfuerzo tributario local (\$) por cada peso de transferencias corrientes y de capital del nivel central de gobierno antes de financiamiento, Colombia 2000-2014

\begin{tabular}{l|c|c|c|c}
\hline \multirow{2}{*}{ Jerarquía Espacial } & \multicolumn{3}{c}{ Administración } \\
\cline { 2 - 5 } & Pastrana & Uribe I & Uribe II & Santos I \\
\hline Zonas Metropolitanas & 4,5 & 2,9 & 2,8 & 3,0 \\
Núcleos Metropolitanos & 4,9 & 3,1 & 3,1 & 3,4 \\
Municipios Metropolizados Próximos & 3,2 & 2,0 & 1,9 & 2,0 \\
Municipios Metropolizados Lejanos & 2,2 & 2,2 & 2,0 & 1,8 \\
\hline Resto del País & 1,8 & 1,2 & 1,2 & 1,3 \\
Crecimiento Robusto & 1,9 & 1,2 & 1,2 & 1,3 \\
Crecimiento Urbano Endeble & 1,8 & 1,2 & 1,2 & 1,2 \\
Crecimiento Rural Endeble & 1,6 & 1,1 & 1,1 & 1,1 \\
Crecimiento Frágil & 1,5 & 1,0 & 1,0 & 1,0 \\
\hline Total & 2,7 & 1,8 & 1,8 & 1,8 \\
\hline
\end{tabular}

Fuente: Cálculos con base en estadísticas del DNP-Departamento Nacional de Planeación. 
manera tan abigarrada los hay y, por tanto, la corrupción es menos aguda. Si se toma como referencia el ranking de percepción de la corrupción (Transparencia Internacional, 2016) en el que Colombia ocupa el lugar 90 entre 176, algunos de estos países son Nueva Zelanda (1), Francia (23), Chile (24), Italia (60), Serbia (72) y China (79). También lo hay en donde con régimen centralista de Estado, la percepción de la corrupción es más elevada como en Perú (101), República Dominicana (120), Ecuador (120) y Guatemala (136), entre otros.

Un modelo centralista no es necesariamente clientelista y corrupto, pero puede llegar a serlo. El clientelismo es la forma más arraigada de relacionamiento del bloque en el poder que controla el nivel central de gobierno en Colombia con las burguesías regionales (cfr. González, 2014; Kalmanovitz, 2017). Los hallazgos fiscales de los entes de control son un buen indicador del saqueo al erario municipal (Alfonso, 2017a). Por su parte, los fallos de la penúltima instancia judicial en relación con los delitos contra la administración pública municipal se incrementaron en $73,6 \%$ en la última administración - ver Tabla 6 -, indicador del que se infiere que la justicia ha estado más activa que en el período precedente, pero también que el modelo centralista tiende a degradarse a ritmos cada vez más acelerados. El peculado por apropiación y las demás modalidades conexas con el detrimento al erario municipal constituyen, de lejos, las formas más enraizadas y perseverantes del detrimento al erario.

\section{Tabla 6 - Delitos contra la administración pública municipal por tipo y período presidencial del fallo condenatorio, Colombia 2007-2014}

\begin{tabular}{|c|c|c|c|c|c|}
\hline \multirow{2}{*}{ Tipo de Delito } & \multicolumn{2}{|c|}{ Uribe II } & \multicolumn{2}{|c|}{ Santos I } & \multirow{2}{*}{$\begin{array}{c}\text { Tasa de } \\
\text { Crecimiento } \\
(\%)\end{array}$} \\
\hline & \# & $\%$ & \# & $\%$ & \\
\hline Peculado & 20.862 & 31,5 & 27.281 & 23,7 & 30,8 \\
\hline Abuso de autoridad y otras infracciones & 14.677 & 22,1 & 27.095 & 23,5 & 84,6 \\
\hline Delitos contra los servidores públicos & 9.289 & 14,0 & 22.856 & 19,9 & 146,1 \\
\hline Prevaricato & 9.800 & 14,8 & 17.906 & 15,6 & 82,7 \\
\hline Celebración indebida de contratos & 5.094 & 7,7 & 9.753 & 8,5 & 91,5 \\
\hline Cohecho & 2.150 & 3,2 & 4.357 & 3,8 & 102,7 \\
\hline Concusión & 1.970 & 3,0 & 2.806 & 2,4 & 42,4 \\
\hline Usurpación y abuso de funciones públicas & 1.593 & 2,4 & 1.780 & 1,5 & 11,7 \\
\hline Enriquecimiento ilícito & 657 & 1,0 & 772 & 0,7 & 17,5 \\
\hline Tráfico de influencias & 205 & 0,3 & 477 & 0,4 & 132,7 \\
\hline Utilización indebida de información & 31 & 0,0 & 52 & 0,0 & 67,7 \\
\hline Total & 66.328 & 100,0 & 115.135 & 100,0 & 73,6 \\
\hline
\end{tabular}

Fuente: Cálculos con base en estadísticas del DNP-Departamento Nacional de Planeación / Fiscalía General de la Nación. 
El fenómeno de la corrupción administrativa en sus diferentes modalidades afecta a la inmensa mayoría de los entes territoriales que hacen parte del modelo territorial de Estado, distribuyéndose en iguales proporciones entre las zonas metropolitanas a la cabeza de la jerarquía espacial y en el resto del país - ver Tabla 7. Si en las 77 jurisdicciones que componen las nueve zonas metropolitanas la corrupción administrativa es más intensa que en el resto del país, tanto en el número de casos como en los montos comprometidos por detrimento al erario, esto se debe a que el tamaño de sus presupuestos es más elevado, lo que se constituye en un poderoso incentivo para que los corruptos de oficio se lucren de ellos. Es decir, que un modelo territorial de Estado centralista-clientelista, entre más elevados sean los presupuestos de gasto mayor será el detrimento al erario, regla de la que deviene la corresponsabilidad del nivel central de gobierno en la persistencia de la corrupción administrativa.

La distribución del poder al calor de un modelo territorial de Estado ha sufrido muchos retoques en las últimas décadas, tales como los ocurridos por sucesivos actos legislativos que modifican la Constitución Política sin llegar a afectar de manera decidida los circuitos anacrónicos en que se fundamenta y que permiten el recrudecimiento de fenómenos como la corrupción administrativa. La redistribución del poder no es fácil de alcanzar debido, entre otras razones, a la prevalencia de los intereses en juego que soportan el statuo quo, especialmente los de los políticos que han invertido cuantiosos recursos para gozar de una posición en el modelo con la que se sienten cómodos. Es por ello que propuestas de reorganización de la división

Tabla 7 - Fallos condenatorios de la justicia por delitos contra la administración pública municipal por jerarquía espacial y período presidencial, Colombia 2007-2014

\begin{tabular}{|c|c|c|c|c|c|}
\hline \multirow{2}{*}{ Jerarquía Espacial } & \multicolumn{2}{|c|}{ Urbe II } & \multicolumn{2}{|c|}{ Santos I } & \multirow{2}{*}{$\begin{array}{c}\text { Tasa de } \\
\text { Crecimiento } \\
(\%)\end{array}$} \\
\hline & \# & $\%$ & $\#$ & $\%$ & \\
\hline Zonas Metropolitanas & 33.516 & 50,5 & 56.109 & 48,7 & 67,4 \\
\hline Núcleos Metropolitanos & 27.778 & 41,9 & 45.917 & 39,9 & 65,3 \\
\hline Municipios Metropolizados Próximos & 5.649 & 8,5 & 10.080 & 8,8 & 78,4 \\
\hline Municipios Metropolizados Lejanos & 89 & 0,1 & 112 & 0,1 & 25,8 \\
\hline Resto del País & 32.812 & 49,5 & 59.026 & 51,3 & 79,9 \\
\hline Crecimiento Robusto & 26.768 & 40,4 & 48.254 & 41,9 & 80,3 \\
\hline Crecimiento Urbano Endeble & 3.690 & 5,6 & 6.904 & 6,0 & 87,1 \\
\hline Crecimiento Rural Endeble & 2.151 & 3,2 & 3.464 & 3,0 & 61,0 \\
\hline Crecimiento Frágil & 203 & 0,3 & 404 & 0,4 & 99,0 \\
\hline Total & 66.328 & 100,0 & 115.135 & 100,0 & 73,6 \\
\hline
\end{tabular}

Fuente: Cálculos con base en estadísticas del DNP-Departamento Nacional de Planeación / Fiscalía General de la Nación. 
político-administrativa y de redistribución del poder en el territorio, son consideradas como una amenaza al statuo quo y son repudiadas por ilusorias o por atentar contra supuestas tradiciones con arraigo cultural.

\section{Las regiones metropolitanas como soportes de un nuevo modelo territorial de Estado}

El polimetropolitanismo o las nueve zonas metropolitanas identificadas, conviven en el territorio colombiano produciendo complejos campos multigravitatorios y, simultáneamente, la finitud de su alcance da lugar a vastas zonas desarticuladas del desarrollo, tal como se esbozó en las Figuras 1 a 3. Otros rasgos deben ser considerados para comprender la delimitación de las regiones metropolitanas. El primero de ellos es que las tres zonas metropolitanas de Pereira, Manizales y Armenia conforman en la práctica una unidad metropolitana a la que se denomina Eje Cafetero, siendo la primera el núcleo metropolitano de tal unidad y, por ella, es empleada como el referente para la regionalización que se propone. El segundo es que hay campos gravitatorios que no son tan complejos como los de la zona andina en donde se entrecruzan varios campos gravitacionales pues, en efecto, las zonas al norte de la zona metropolitana de Barranquilla, al sur de la de Cali, al occidente de la del Valle de Aburrá y al oriente de la de Bogotá, son parte de sus campos monogravitacionales - ver Figura 4.

El modelo empleado es el de la ecuación (5), salvo que se empleó el Producto Interno Bruto municipal del 2015 en reemplazo de la medida comúnmente empleada que es la población. Varias razones justifican esta decisión. La primera es la aducida inconveniencia del empleo de las proyecciones poblacionales por cuanto subestiman la trayectoria que experimentan las zonas metropolitanas desde 1950, sin exponer las causas que soportan una posible bifurcación del crecimiento poblacional metropolitano hacia otras zonas del país (cfr. Alfonso, 2017b). La segunda es que, siguiendo la regla de Reilly, la población expresa una demanda potencial que, al no considerar fenómenos como la funcionalidad de los equipamientos de los lugares, la aglomeración de las actividades y sus encadenamientos y la productividad de los recursos, esto es, los factores de oferta, introduce un sesgo al cálculo gravitatorio. Por tal razón, el valor agregado de las economías locales es una medida que capta de manera sintética la masa que entra en juego en los campos gravitatorios.

Las regiones metropolitanas son por naturaleza heterogéneas $y$, sin embargo, se detectan ciertas regularidades. Una de las más notables es que el escalonamiento en el área superficial de ellas guarda estrecha relación con la magnitud de la creación de riqueza en las zonas metropolitanas, esto es, el valor agregado o PIB metropolitano. Este resultado es revelador como para justificar la pertinencia de ejercicios de regionalización como éste que, como se advirtió, tiene la pretensión de proponer una reorganización político-administrativa del territorio colombiano con la que se pueda alterar el modelo territorial de Estado centralista que constriñe el aprovechamiento del potencial de la riqueza del país. Tal pretensión suscita 
Figura 4 - Regiones metropolitanas de Colombia

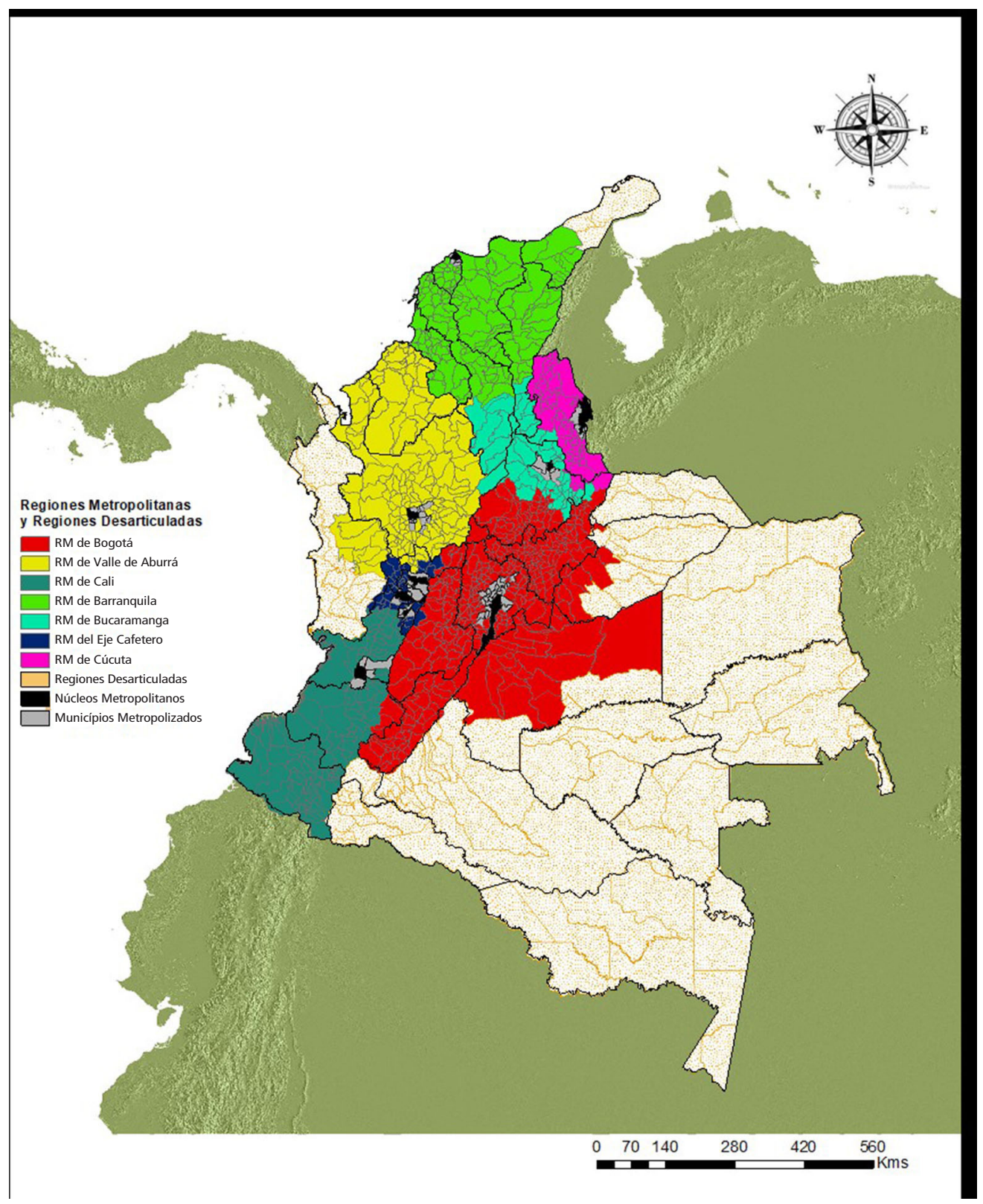

Fuente: Cálculos con base en estadísticas del Dane-Departamento Administrativo Nacional de Estadística y www.lasdistancias.com. 
críticas como las culturalistas que amparan el statuo quo regional, como ocurrirá con el caso de la discutible región de Caribe que, como se advierte en la Figura 4, está fragmentada en el área de influencia de la zona metropolitana de Barranquilla y en la del Valle de Aburrá, hecho poco novedoso pues se sabe de tiempo atrás el empuje de las migraciones antioqueñas hacia los municipios del Departamento de Córdoba.

\section{Caracterización de las regiones metropolitanas}

Las regionalizaciones del territorio colombiano de 1998 y 2001 se diferencian de la mayoría de las realizadas con anterioridad por haber ofrecido caracterizaciones socio-económicas y ambientales de soporte a sus propuestas. Las caracterizaciones son un componente infaltable en propuestas de esta naturaleza. En el territorio desarticulado del desarrollo territorial colombiano basado en las zonas metropolitanas reside el $4,1 \%$ de la población - ver Tabla 8. La región metropolitana más pequeña es la de Cúcuta que acoge al 2,8\% de los residentes en Colombia, participación que seguramente aumentará a medida que se agudice la crisis política en Venezuela. Salvo en las regiones metropolitanas de Cali y Barranquilla, la primacía poblacional de las zonas metropolitanas es bastante aguda, denotando esto el contraste de los modelos de ocupación desconcentrados en el caso de estas dos regiones, y muy concentrados en las cinco restantes. Por su parte, al crecimiento poblacional endeble - urbano y rural - así como el frágil, se encuentra vinculado el $11,5 \%$ de la población residente, estando ella localizada principalmente en las regiones metropolitanas de Bogotá y de Cali.

Tabla 8 - Distribución de la población en las regiones metropolitanas, Colombia 2015

\begin{tabular}{|c|c|c|c|c|c|c|c|c|c|c|}
\hline \multirow{2}{*}{$\begin{array}{c}\text { Región } \\
\text { Metropolitana }\end{array}$} & \multicolumn{4}{|c|}{ Zonas Metropolitanas } & \multicolumn{5}{|c|}{ Resto de la Región Metropolitana } & \multirow[b]{2}{*}{ Total } \\
\hline & Núcleo & $\begin{array}{l}\text { Metropolizado } \\
\text { Próximo }\end{array}$ & $\begin{array}{c}\text { Metropolizado } \\
\text { Lejano }\end{array}$ & $\begin{array}{l}\text { Sub- } \\
\text { total }\end{array}$ & Robusto & $\begin{array}{l}\text { Urbano } \\
\text { Endeble }\end{array}$ & $\begin{array}{l}\text { Rural } \\
\text { Endeble }\end{array}$ & Frágil & $\begin{array}{l}\text { Sub- } \\
\text { total }\end{array}$ & \\
\hline Bogotá & 16,3 & 3,4 & 0,1 & 19,8 & 10,6 & 2,0 & 1,0 & 0,0 & 13,7 & 33,4 \\
\hline Valle de Aburrá & 5,1 & 3,3 & 0,1 & 8,5 & 7,6 & 0,8 & 0,8 & 0,0 & 9,2 & 17,7 \\
\hline Cali & 4,9 & 1,3 & - & 6,2 & 6,3 & 2,0 & 0,6 & 0,1 & 9,1 & 15,3 \\
\hline Barranquilla & 2,5 & 1,7 & - & 4,2 & 9,8 & 1,3 & 0,6 & 0,3 & 12,0 & 16,2 \\
\hline Bucaramanga & 1,1 & 1,3 & - & 2,4 & 1,5 & 0,3 & 0,2 & - & 1,9 & 4,3 \\
\hline Eje Cafetero & 2,4 & 1,6 & - & 4,0 & 0,7 & 0,1 & 0,3 & 0,1 & 1,1 & 5,2 \\
\hline Cúcuta & 1,3 & 0,4 & - & 1,7 & 0,7 & 0,2 & 0,2 & - & 1,1 & 2,8 \\
\hline Desarticuladas & - & - & - & - & 4,4 & 0,3 & 0,2 & 0,1 & 5,0 & 5,0 \\
\hline Total & 33,8 & 13,0 & 0,1 & 46,9 & 41,6 & 7,0 & 3,9 & 0,6 & 53,1 & 100,0 \\
\hline
\end{tabular}

Fuente: Elaborada con base en las proyecciones poblacionales del Dane-Departamento Administrativo Nacional de Estadística. 
El $77,6 \%$ de la población colombiana reside en una porción relativamente marginal del territorio colombiano, el 0,46\%. Si bien la urbanización de la población acarrea externalidades negativas tales como la polución en sus diferentes manifestaciones, la densidad de ocupación es una de sus externalidades positivas pues, de lo contrario, su dispersión en el territorio acarrearía mayor deterioro ambiental. Los núcleos metropolitanos son los más densamente poblados y, por tanto, es en ellos en donde se hace un uso más intenso del suelo urbanizado. El escalonamiento de allí en sentido descendente guarda relación con la jerarquía propuesta, resultado que en buena medida valida la pertinencia de la regionalización propuesta. Sin embargo, más allá de tal verificación, estos resultados plantean la potencialidad de los municipios de crecimiento robusto para acoger más población sin requerir más suelo urbanizado que el existente, con lo que las regiones metropolitanas podrían asumir estrategias desconcentrativas del crecimiento de la población con un criterio básico de sostenibilidad, y es que la expansión urbana sea la última de las opciones consideradas para tal propósito.

La concentración de la producción de riqueza en las zonas metropolitanas también guarda relación con la jerarquía propuesta ver Tabla 9. El 53,8\% del PIB se produce en estas zonas y el $38,0 \%$ en los municipios de crecimiento robusto. La zona metropolitana de Bogotá es tres veces superior a la del Valle de Aburrá en actividad económica. El desequilibrio es evidente. No obstante, hay indicios de que el desarrollo regional basado en las políticas para las regiones metropolitanas puede ser menos desequilibrado. La productividad aparente del trabajo en Bucaramanga es más elevada que la de Bogotá y Medellín, mientras que la de su entorno regional también lo es, jalonada principalmente por la economía petrolera de Barrancabermeja. Estos resultados lo que sugieren es la posibilidad latente de una subregionalización de las regiones metropolitanas con fines de activación de las fuentes del crecimiento regional sin desactivar las aglomeraciones ya creadas y que, en consonancia con el argumento precedente del crecimiento sostenible, tiene mayor potencial que se ha estado intentando alcanzar de tiempo atrás con el modelo territorial de Estado centralista.

La supresión de los 32 departamentos y el encargo de la responsabilidad de la coordinación municipal a las siete regiones metropolitanas es la reforma estructural de partida que da lugar a una nueva organización político-administrativa más eficaz y con menos incentivos para la corrupción administrativa. La nueva organización que entraña una redistribución del poder plantea nuevas órbitas funcionales que, en materia de desarrollo territorial por ejemplo, demandan de las regiones metropolitanas del Valle de Aburrá, Eje Cafetero y Cali, asumir compromisos con la integración del Chocó y del Cauca desarticulados, implicándoles otro tanto a las de Bogotá, Cali y, en menor medida a las de Bucaramanga y Cúcuta, con el desarrollo sostenible orinoquense y amazónico. Éstas, como otras órbitas funcionales de las regiones metropolitanas, exigen esfuerzos de diversa naturaleza en la búsqueda de un nuevo orden político que modernice al Estado desde los territorios. Uno de ellos, el más impopular, es el que atañe al incremento de los recaudos de los tributos locales. 
Tabla 9 - Distribución del valor agregado en las regiones metropolitanas, Colombia 2015

\begin{tabular}{|c|c|c|c|c|c|c|c|c|c|c|}
\hline \multirow{2}{*}{$\begin{array}{c}\text { Región } \\
\text { Metropolitana }\end{array}$} & \multicolumn{4}{|c|}{ Zonas Metropolitanas } & \multicolumn{5}{|c|}{ Resto de la Región Metropolitana } & \multirow[b]{2}{*}{ Total } \\
\hline & Núcleo & $\begin{array}{l}\text { Metropolizado } \\
\text { Próximo }\end{array}$ & $\begin{array}{c}\text { Metropolizado } \\
\text { Lejano }\end{array}$ & $\begin{array}{l}\text { Sub- } \\
\text { total }\end{array}$ & Robusto & $\begin{array}{l}\text { Urbano } \\
\text { Endeble }\end{array}$ & $\begin{array}{l}\text { Rural } \\
\text { Endeble }\end{array}$ & Frágil & $\begin{array}{l}\text { Sub- } \\
\text { total }\end{array}$ & \\
\hline Bogotá & 25,5 & 3,5 & 0,0 & 29,0 & 11,6 & 2,5 & 0,6 & 0,0 & 14,8 & 43,8 \\
\hline Valle de Aburrá & 6,1 & 4,0 & 0,0 & 10,1 & 4,7 & 0,5 & 0,6 & 0,0 & 5,9 & 15,9 \\
\hline Cali & 4,6 & 2,1 & - & 6,7 & 4,2 & 1,1 & 0,4 & 0,1 & 5,7 & 12,4 \\
\hline Barranquilla & 2,8 & 0,9 & - & 3,6 & 7,1 & 0,6 & 0,3 & 0,1 & 8,1 & 11,7 \\
\hline Bucaramanga & 1,8 & 1,4 & - & 3,2 & 3,6 & 0,2 & 0,1 & - & 3,9 & 7,2 \\
\hline Eje Cafetero & 2,0 & 1,1 & - & 3,1 & 0,5 & 0,0 & 0,2 & 0,1 & 0,8 & 4,0 \\
\hline Cúcuta & 0,9 & 0,2 & - & 1,2 & 0,4 & 0,1 & 0,1 & - & 0,6 & 1,7 \\
\hline Desarticuladas & - & - & - & - & 3,2 & 0,1 & 0,1 & 0,0 & 3,4 & 3,4 \\
\hline Total & 43,6 & 13,1 & 0,1 & 56,8 & 35,3 & 5,2 & 2,4 & 0,3 & 43,2 & 100,0 \\
\hline
\end{tabular}

Fuente: Elaborada con base en estadísticas del Dane-Departamento Administrativo Nacional de Estadística.

La tributación a la propiedad como soporte de la modernización del Estado desde las regiones metropolitanas

La financiación del desarrollo en las regiones metropolitanas es posible con mayores grados de autonomía, que solamente es posible quebrando gradualmente sus vínculos con el centralismo. La responsabilidad del nivel central de gobierno no se diluye con este propósito. Los mayores grados de autonomía son posibles de alcanzar con la sustitución de la tributación al fisco nacional por la que se hace a los fiscos locales. Esta decisión puede acarrear beneficios redistributivos considerables al reducir, por ejemplo, el impuesto al valor agregado que es un gravamen considerablemente regresivo por el de la tributación a la propiedad que es progresivo. ¿Hay margen para ello? La tasa efectiva del recaudo del impuesto predial en las zonas urbanas es, en promedio, del 5,1 por mil - ver Tabla 10, cuando la tarifa máxima es del 14,0 por mil. Ese resultado es la combinatoria de los gravámenes a bienes de diferente uso y por tanto diferentes, como también de lo actualizado o retrasado que se encuentre el avalúo predial frente a los precios de mercado de los activos inmobiliarios. La tributación a la propiedad en la zona metropolitana de Bogotá es, en promedio, relativamente más baja que en el resto, especialmente en comparación con el Valle de Aburrá y Cali. El recaudo efectivo en las zonas rurales es de $\$ 2,4$ por cada $\$ 1.000$ de avalúo - ver Tabla 11 - y es en estas zonas en donde se presentan los retardos más prolongados en la actualización y, además, las inequidades más considerables puesto 
Tabla 10 - Tasa efectiva de recaudo del impuesto predial urbano, Colombia 2015

\begin{tabular}{|c|c|c|c|c|c|c|c|c|c|c|}
\hline \multirow{2}{*}{$\begin{array}{c}\text { Región } \\
\text { Metropolitana }\end{array}$} & \multicolumn{4}{|c|}{ Zonas Metropolitanas } & \multicolumn{5}{|c|}{ Resto de la Región Metropolitana } & \multirow[b]{2}{*}{ Total } \\
\hline & Núcleo & $\begin{array}{l}\text { Metropolizado } \\
\text { Próximo }\end{array}$ & $\begin{array}{c}\text { Metropolizado } \\
\text { Lejano }\end{array}$ & $\begin{array}{l}\text { Sub- } \\
\text { total }\end{array}$ & Robusto & $\begin{array}{l}\text { Urbano } \\
\text { Endeble }\end{array}$ & $\begin{array}{l}\text { Rural } \\
\text { Endeble }\end{array}$ & Frágil & $\begin{array}{l}\text { Sub- } \\
\text { total }\end{array}$ & \\
\hline Bogotá & 4,5 & 6,1 & 3,4 & 4,6 & 5,6 & 5,5 & 5,0 & 4,6 & 5,6 & 4,7 \\
\hline Valle de Aburrá & 7,3 & 6,1 & 3,1 & 6,9 & 4,0 & 5,3 & 6,7 & 3,0 & 4,3 & 6,5 \\
\hline Cali & 6,9 & 7,7 & - & 7,0 & 5,6 & 4,8 & 5,1 & 5,8 & 5,4 & 6,5 \\
\hline Barranquilla & 5,3 & 3,2 & - & 4,9 & 4,1 & 1,6 & 2,8 & 4,3 & 4,0 & 4,3 \\
\hline Bucaramanga & 5,6 & 6,0 & - & 5,8 & 5,0 & 4,0 & 2,4 & - & 4,8 & 5,6 \\
\hline Eje Cafetero & 6,7 & 3,3 & - & 5,9 & 5,6 & 9,0 & 4,8 & 6,7 & 5,5 & 5,8 \\
\hline Cúcuta & 3,3 & 4,3 & - & 3,4 & 3,0 & 1,5 & 2,7 & - & 2,8 & 3,3 \\
\hline Desarticuladas & - & - & - & - & 2,8 & 3,8 & 5,3 & 1,5 & 2,8 & 2,8 \\
\hline Total & 5,1 & 5,7 & 3,4 & 5,2 & 4,7 & 4,6 & 4,8 & 4,8 & 4,7 & 5,1 \\
\hline
\end{tabular}

Fuente: Elaborada con base en estadísticas del Departamento Administrativo Nacional de Estadística y del Departamento Nacional de Planeación.

Tabla 11 - Tasa efectiva de recaudo del impuesto predial rural, Colombia 2015

\begin{tabular}{|c|c|c|c|c|c|c|c|c|c|c|}
\hline \multirow{2}{*}{$\begin{array}{c}\text { Región } \\
\text { Metropolitana }\end{array}$} & \multicolumn{4}{|c|}{ Zonas Metropolitanas } & \multicolumn{5}{|c|}{ Resto de la Región Metropolitana } & \multirow[b]{2}{*}{ Total } \\
\hline & Núcleo & $\begin{array}{l}\text { Metropolizado } \\
\text { Próximo }\end{array}$ & $\begin{array}{c}\text { Metropolizado } \\
\text { Lejano }\end{array}$ & $\begin{array}{l}\text { Sub- } \\
\text { total }\end{array}$ & Robusto & $\begin{array}{l}\text { Urbano } \\
\text { Endeble }\end{array}$ & $\begin{array}{l}\text { Rural } \\
\text { Endeble }\end{array}$ & Frágil & $\begin{array}{l}\text { Sub- } \\
\text { total }\end{array}$ & \\
\hline Bogotá & - & 2,8 & 1,0 & 2,4 & 2,1 & 3,2 & 1,7 & 1,1 & 2,4 & 2,4 \\
\hline Valle de Aburrá & 7,4 & 5,4 & 6,0 & 5,8 & 1,3 & 1,8 & 1,9 & 2,2 & 1,4 & 3,1 \\
\hline Cali & - & 4,5 & - & 3,8 & 1,7 & 1,0 & 2,0 & 1,2 & 1,6 & 2,5 \\
\hline Barranquilla & 3,5 & - & - & 1,1 & 0,4 & 0,2 & 0,3 & - & 0,4 & 0,5 \\
\hline Bucaramanga & - & 4,7 & - & 4,6 & 2,5 & 2,1 & 4,2 & - & 2,6 & 3,5 \\
\hline Eje Cafetero & 3,0 & 9,0 & - & 5,6 & 3,3 & 1,6 & 1,9 & 3,1 & 2,9 & 4,8 \\
\hline Cúcuta & - & 2,1 & - & 0,4 & 2,4 & 0,8 & 1,1 & - & 2,1 & 1,4 \\
\hline Desarticuladas & - & - & - & - & 0,6 & 0,0 & 0,1 & 0,4 & 0,5 & 0,5 \\
\hline Total & 2,3 & 3,9 & 2,6 & 3,5 & 1,4 & 2,3 & 1,6 & 1,0 & 1,6 & 2,4 \\
\hline
\end{tabular}

Fuente: Elaborada con base en estadísticas del Dane y del DNP-Departamento Nacional de Planeación. 
que los latifundios improductivos tributan regularmente menos que los minifundios, la pequeña y la mediana propiedad.

La respuesta afirmativa a la cuestión planteada del margen surge tanto de la constatación de que al interior de las estructuras tributarias a la propiedad en las regiones metropolitanas es posible incrementar la tasa efectiva de recaudo introduciendo más equidad tributaria, como en el hecho de que la tarifa del impuesto al valor agregado podría reducirse y, con ello, los ingresos corrientes de la Nación y, por tanto, las transferencias a los entes territoriales. Las ganancias en autonomía fiscal y financiera serían considerables, pero simultáneamente sería esperable una reducción significativa en la corrupción al suscitar esa sustitución mayor interés en la fiscalización ciudadana a la utilización de los recursos públicos y, además, la posibilidad de introducir compromisos de solidaridad financiera intermunicipal en las órbitas funcionales de las nuevas regiones metropolitanas.

Una simulación permite ilustrar los órdenes de magnitud de esta iniciativa. Si se elevara la tributación efectiva a la propiedad urbana al 8,0 por mil y la rural al 6,0 por mil, introduciendo equidad por la vía de la actualización de los avalúos prediales y la actualización de las tarifas diferenciales por destinación o uso de los activos inmobiliarios, el recaudo se incrementaría en US\$1.057 millones por año. Esta suma equivale a aproximadamente el $10 \%$ de las transferencias corrientes y de capital de nivel central de gobierno a los municipios, de manera que con ajustes periódicos de esta naturaleza acompañada de una paulatina desgravación de bienes del impuesto al valor agregado, y de la disminución de la tarifa, en 10 años o menos se alcanzaría la autonomía fiscal y financiera de estos entes territoriales introduciendo, simultáneamente, equidad. En apoyo a tal propósito, las regiones metropolitanas estarían en capacidad de cristalizar el principio de solidaridad financiera intermunicipal con los tributos que actualmente captan los departamentos.

\section{Reflexiones finales: las regiones metropolitanas como soporte de un nuevo modelo territorial de Estado}

El modelo territorial de Estado centralista colombiano es usado para la reproducción política al calor de una forma de distribución del poder basada, principalmente, en el clientelismo. La creciente corrupción administrativa en los entes territoriales es subyacente a este modelo. La coordinación territorial en materia económica, fiscal y ambiental es muy compleja cuando se realiza desde un nivel central de gobierno que, a su vez, procura la unidad y coherencia de la sociedad. Es por ello que el control territorial a través de las transferencias fiscales para que los entes territoriales sirvan como ejecutores de programas nacionales es el mejor recurso a emplear por el centralismo a fin de que el statuo quo territorial no sea afectado, como en la práctica se ha hecho, pero cuyo costo es muy elevado. La pérdida gradual de autonomía local con la consecuente pérdida de un potencial de riqueza desperdiciado. Se intuye que el cambio de modelo arrojaría más beneficios que los costos que entraña 
una reforma de esta envergadura, pero la oposición a la modernización del Estado desde los territorios es considerable en vista de la amplitud y amalgama de agentes políticos cooptados por tal modelo.

En un contexto como éste se torna imperiosa la necesidad de propuestas alternativas a la preservación del statuo quo las que, por supuesto, serán juzgadas como utópicas. Estas utopías pueden tornarse posibles en escenarios de cambio democrático como el que se presume pueda acaecer con la superación del conflicto interno armado. Es decir, la paz es un accidente histórico que debe ser aprovechado estratégicamente para modificar un contexto propicio para el resurgimiento de las causas que ocasionaron el conflicto interno armado y su excesiva prolongación en el tiempo.

Las regiones metropolitanas son viables en tanto ellas operan de hecho. Si la división político-administrativa en curso se traslapa con ellas, es porque el modelo territorial de Estado así lo prescribe. Es decir, que la distribución del poder en curso antagoniza con las dinámicas supra-jurisdiccionales de organización y ocupación del territorio y, por tal razón, la coordinación aludida es estructuralmente ineficaz. Las regiones metropolitanas gozan de una capacidad intrínseca para promover niveles de autonomía más elevados $y$, con ello, lograr desencapsular el crecimiento económico local, la equidad social y la reproductibilidad ecológica inmanentes a un modelo más virtuoso que el centralista. El esfuerzo fiscal requerido para alcanzar mayores grados de autonomía se pueden lograr introduciendo simultáneamente equidad y, por tanto, sería un costo tolerable que rendiría sus frutos en el corto plazo pues, según se argumentó, tan solo tomaría una década alcanzar la plena autonomía fiscal municipal, más aún cuando después de treinta años de descentralización Colombia es más centralista que lo que fue a comienzos de tal proceso.

\section{Óscar A. Alfonso R.}

Universidad Externado de Colombia, Facultad de Economía. Bogotá, Colombia.

oscar.alfonso@uexternado.edu.co 


\section{Referencia}

ALFONSO R., Ó. (2010). "Profundización de las relaciones de metropolización de Bogotá con la Sabana". En: JARAMILLO, S. (ed.) Bogotá en el cambio de siglo: promesas y realidades. Colección Ciudades, v. 4. Quito, Organización Latinoamericana de Centros Históricos.

(2012). "Dialectique de l'intervention de l'État dans la zona métropolitaine de Bogotá". En: TELLIER, L.-N. y VAINER, C. B. Métropoles des Amériques en Mutation. Québec/Canadá, Presses de I'Université du Quebec.

(2014a). Los desequilibrios territoriales en Colombia: Estudios sobre el sistema de ciudades y el polimetropolitanismo. Colección Economía Institucional Urbana, n. 9. Bogotá, Universidad Externado de Colombia.

(2014b). "Colombia, un país de regiones metropolitanas centralmente fiscalizado". En: COVILLA MARTíNEZ, J. C. y LONDOÑO ULLOA, J. E. (eds.). ¿Unitaria o federal? Estudios sobre la configuración del nivel intermedio en Colombia y algunas referencias internacionales. Bogotá, Colciencias - Universidad Externado de Colombia.

(2017a). El oficio del corrupto y el detrimento al erario en el modelo territorial de Estado centralista-clientelista colombiano. Inédito. Bogotá, Facultad de Economía - Universidad Externado de Colombia.

(2017b). El "boom" de las ciudades intermedias es un mito, al menos en Colombia: Un análisis de la trayectoria dependiente de la urbanización de la población. Inédito. Bogotá, Facultad de Economía - Universidad Externado de Colombia.

ARELLANO, R. (1997). “Nuevas alternativas a la descentralización fiscal en México”. En: CHÁVEZ, A. H. (coord.) ¿Hacia un nuevo federalismo? Serie Estudios Fideicomiso Historia de las Américas. México, El Colegio de México - Fondo de Cultura Económica.

CHASCO L., P. (2000). Modelos de gravitación comercial: una aplicación al anuario comercial de España. Documento de trabajo, Instituto L. R. Klein - Universidad Autónoma de Madrid. Disponible en: https://www.uam.es/otroscentros/klein/docjor/pchasco.pdf. Acesso en: 27 mar 2017.

COMISIÓN DE LAS COMUNIDADES EUROPEAS (1992). Urbanización y funciones de las ciudades en la Comunidad Europea. Bruselas - Luxemburgo, Oficina de Publicaciones Oficiales de la Comunidad Europea.

DAUGHTERS, R. y HARPER, L. (2006). "Reformas de descentralización fiscal y política". En: LORA, E. (ed.). El estado de las reformas del Estado en América Latina. Washington, BID - Banco MundialMayol Ediciones.

ESQUIVEL T., R. (2003). Fronteras desestabilizadoras de Colombia. Fronteras, Territorios y Metáforas. Bogotá, Hombre Nuevo Editores.

GONZÁLEZ, F. (2014). Poder y violencia en Colombia. Colección Territorio, Poder y Conflicto. Bogotá, Odecofi-Cinep.

HAESBERT, R. (2014). Viver no limite: Território e multi/transterritorialidade em tempos de insegurança e contenção. Rio de Janeiro, Bertrand Brasil. 
HOENISGSBERG, H. F. (1977). La crisis poblacional. Bogotá, Universidad de los Andes, Editorial Presencia.

HUGOUNENQ, R.; J. LE CACHEUX y TH. MADIES. (1999). Diversité des fiscalités européennes et risques de concurrence fiscale. Revue de l'OFCE, n. 70.

IDEAM (2011). Clasificaciones climáticas Colombia. Disponible en: http://www.ideam.gov.co/ documents/21021/21789/climas+\%5BModo+de+compatibilidad\%5D.pdf/d8c85704-a07a-4290ba65-f2042ce99ffg. Acesso en: 30 abr 2017.

ISARD, W. (1960). Métodos de análisis regional: una introducción a la ciencia regional. Cambridge, MA, The MIT Press.

JARAMILLO GONZÁLEZ, S. y ALFONSO, Ó. (2001). “Un análisis de las relaciones de metropolización a partir de los movimientos migratorios". En: ALFONSO, Ó. y JARAMILLO GONZÁLEZ, S. (eds.). Ciudad y región en Colombia: nueve ensayos de análisis socioeconómico y espacial. Bogotá, Universidad Externado de Colombia.

KALMANOVITZ, S. (2017). Corrupción y clientelismo. Diario El Espactador (20/2/2017). Constitución Política de Ciudad de México. Disponible en: http://www.cdmx.gob.mx/constitucion. Legalfrance. https://www.legifrance.gouv.fr/affichTexte.do?cidTexte=JORFTEXT000028526298

LEFÈVRE, CH. (2014). Gobernar las metrópolis o el gobierno de las metrópolis. La utopía metropolitana I. Colección Economía Institucional Urbana, n. 10. Bogotá, Universidad Externado de Colombia.

MADIES, TH. (1997). Concurrence fiscal et intercommunalité. Revue de l'OFCE, n. 63.

(2001). Fiscalité superposée et externalités fiscales verticals: faut-il reconsidérer le débat entre concurrence et coopeération fiscales? L'Actualité économique. Montreal, v. 77, n. 4.

MOLINA, H. y P. MORENO, P. (2001). "Aportes para una nueva regionalización del territorio colombiano". En: ALFONSO, Ó. y JARAMILLO GONZÁLEZ, S. (eds.). Ciudad y región en Colombia : nueve ensayos de análisis socioeconómico y espacial. Bogotá, Universidad Externado de Colombia.

PIPERNO, S.; PIAZZA, S. y POLA, G. (2014). "Desarrollo urbano e interdependencia fiscal en el área metropolitana de Turín: una exploración preliminar". En: LEFÈVRE, C. et al. La Utopía Metropolitana I. Bogotá, Universidad Externado de Colombia.

PRAGER, J-C. y J-F. THISSE (2010). Économie géographique du développement. Collection Repères. Paris, La Découverte.

REILLY, W. J. (1931). The law of gravitation. New York, W. J. Reilly Inc.

REVÉIZ, É. (2016). La transgresión moral de las élites y el sometimiento de los Estados. Bogotá, Academia Colombiana de Ciencias Económicas.

RODRÍGUEZ G., J. C. (2014). "Tensiones políticas alrededor del federalismo colombiano en el siglo XIX". En: COVILLA MARTÍNEZ, J. C. y LONDOÑO ULLOA, J. E. (eds.) ¿Unitaria o federal? Estudios sobre la configuración del nivel intermedio en Colombia y algunas referencias internacionales. Bogotá, Colciencias - Universidad Externado de Colombia.

SARMIENTO, L. y D. CASTILLO. (1998). "Regiones y divisiones territoriales en la historia de Colombia". En: Municipios y regiones: una mirada desde la sociedad civil. Bogotá, Fundación Social. 
SINDICATO PARIS METROPOLE (2012). Livre (ou)vert Pour une metrópole durable: quelle gouvernance? Disponible en: http://www.parismetropole.fr/ressources/actualites/actualites-de-pm/article/ paris-metropole-devoile-son-livre-vert-sur-la-gouvernance. Acesso en: 8 dez 2013.

SNOW, D. (1976). "The Climate of Northern South America”. En: SCHWERDTFEGER, W. (ed.). Climates of Central and South America. Amsterdam, Elsevier.

TERRAZA, H.; D. RUBIO BLANCO y F. VERA. (2017). De ciudades emergentes a ciudades sostenibles: comprendiendo y proyectando las metrópolis del siglo XXI. Santiago de Chile, BID - Ediciones ARQ.

TRANSPARENCIA INTERNACIONAL (2016). Corruption Perception Index 2016. Disponible en: https://www. transparency.org/news/feature/corruption_perceptions_index_2016. Acesso en: 22 set 2017.

WEINGAST, B. R. (2006). Second Generation Fiscal Federalism: Implications for Decentralized Democratic Governance and Economic Development. Disponible en: SSRN: http://ssrn.com/ abstract=1153440 o http://dx.doi.org/10.2139/ssrn.1153440.

Texto recebido em 16/maio/2017

Texto aprovado em 26/jul/2017 
